\title{
The Use of Low-Potential Energy Sources Based on Organic Rankine Cycle
}

\author{
Denis I. Karabarin and Sergei A. Mihailenko* \\ Siberian Federal University \\ 79 Svobodny, Krasnoyarsk, 660041, Russia
}

Received 19.04.2018, received in revised form 17.09.2018, accepted 05.10.2018

\begin{abstract}
This article shows the efficiency of utilization of low-potential waste energy on various examples in the energy industry. First, the choice of the technology of organic Rankine cycle as a technology of utilization or conversion of low-potential energy is justified. Secondly, requirements to the working bodies used in this technology are formulated. Third, the proposed options for combining this technology and: solar energy; bioenergy; geothermal energy, as well as the superstructure of the organic cycle for heat recovery from the gas turbine and hot water boiler, with an assessment of the potential of the implementation. Examples of implementation of this technology by major manufacturers around the world are presented.
\end{abstract}

Keywords: organic Rankine cycle, utilization of low-grade heat, energy efficiency, low-temperature working bodies.

Citation: Karabarin D.I., Mihailenko S.A. The use of low-potential energy sources based on organic Rankine cycle, J. Sib. Fed. Univ. Eng. technol., 2018, 11(7), 867-876. DOI: 10.17516/1999-494X-0101.

\section{Использование низкопотенциальных источников энергии на основе органического цикла Ренкина}

\author{
Д.И. Карабарин, С.А. Михайленко \\ Сибирский федеральный университет \\ Россия, 660041, Красноярск, пр. Свободный, 79
}

Эта статья показывает эффективность утилизации низкопотенциальной сбросной энергии
на различных примерах в энергетической отрасли. Во-первых, обоснован выбор именно
технологииорганического циклаРенкинав качестветехнологииутилизацииилипреобразования
низкопотенцилльой энергии. Во-вторых, сформулированы требования к рабочим телам,
используемым в данной технологии. В-третьих, предложены варианть комбинирования
данной технологии и: солнечной энергетикой, биоэнергетикой, геотермальной энергетикой, а

(C) Siberian Federal University. All rights reserved

This work is licensed under a Creative Commons Attribution-NonCommercial 4.0 International License (CC BY-NC 4.0).

* Corresponding author E-mail address: DKarabarin@sfu-kras.ru, SMihailenko@sfu-kras.ru 
также надстройкой органического цикла для утилизации тепла от газотурбинной установки и водогрейного котла с оценкой потенциала от внедрения. Представлены примеры внедрения данной технологии основными производителями по всему миру.

Ключевые слова: органический иикл Ренкина, утилизаиия низкопотенциального тепла, энергоэффективность, низкотемпературные рабочие тела.

\section{Введение}

Актуальность данного направления обосновывается важнейшим направлением Энергетической программы (до 2020 г.), принятой Правительством РФ в 2003 г., - энергосбережение во всех отраслях промышленности. Во-первых, энергосбережение предполагает внедрение новых технологических процессов, в основе которых заложена меньшая энергоемкость по сравнению с существующими технологиями. Во-вторых, использование низкопотенциальной энергии, которая на современном уровне развития энергетики еще мало применяется, что приводит к снижению коэффициента использования теплоты сгорания топлива в различных технологиях, основанных на применении органического топлива как источника тепловой энергии. Кроме того, сброс низкопотенциальной энергии вызывает тепловое загрязнение окружающей среды.

Таким образом, использование низкопотенциальной энергии как фактор энергосбережения - одна из народно-хозяйственных задач.

В условиях быстрого роста цен на органическое топливо энергосбережение во всех отраслях промышленности является важнейшим фактором снижения себестоимости производства продукции и повышения ее конкурентной способности. Основные направления энергосбережения:

- использование низкопотенциальной энергии промышленных предприятий;

- создание простых и надежных энергетических установок для производства тепловой и электрической энергии, работающих на местных видах топлива;

- повышение коэффициента использования теплоты топлива на энергетических установках, обеспечивающих тепловой энергией ЖКХ страны.

Решение перечисленных проблем сдерживается отсутствием на отечественном энергетическом рынке установок, позволяющих утилизировать тепловую энергию с низкими параметрами теплоносителей.

Принято считать, что источник энергии является низкопотенциальным, если его температура не превышает 500-570 К (230-300 $\left.{ }^{\circ} \mathrm{C}\right)$. Принципиально низкотемпературные рабочие тела (НРТ) можно разделить на две группы, определяющие тип термодинамического цикла, состав оборудования и технико-экономические показатели силовых установок. В первую группу входят чистые (несмесевые) НРТ: углеводороды (бутан, пропан, пентан), хладоны (R11, R12, R114, R123, R245fa), аммиак, толуол, дифенил, силиконовое масло и др. Они используются в энергоустановках, реализующих конденсационный цикл Ренкина (рис. 1), который в зарубежной научно-технической литературе получил название «organic Rankine cycle» (ORC). Этот цикл находит применение большей частью на тепловых электростанциях: геотермальных; сжигающих мусор или биомассу; солнечных (с концентраторами); утилизирующих бросовую теплоту промышленных предприятий, газотурбинных установок, 
двигателей внутреннего сгорания и т. п., а также для непосредственного привода насосов и нагнетателей.

В качестве НРТ применяют фреоны, водный раствор аммиака, пентан, изопентан, изобутан и др.

При выборе НРТ должны соответствовать ряду требований:

- дешевизна;

- хорошие теплофизические свойства (максимум работы при минимальных параметрах);

- НРТ не должен быть ядовитым;

- отсутствие экологического воздействия на окружающую среду (озоновый слой, парниковый эффект),

- замерзание при достаточно низких отрицательных температурах, что важно для климатических условий России;

- желательно, чтобы пограничная кривая пара в T-S-координатах имела положительную производную, т.е. процесс расширения в турбине заканчивается в области перегретого пара, что исключает эрозию лопаток и не требует перегрева пара перед турбиной.

Анализы показывают, что для значений температур греющих теплоносителей в диапазоне 140-190 ${ }^{\circ} \mathrm{C}$ целесообразно применять в утилизационном контуре пентан, критические параметры которого имеют значения 33,7 бар, $196,6^{\circ} \mathrm{C}$. Однако в конденсаторе пентановой установки приходится поддерживать температуру 50-60 ${ }^{\circ} \mathrm{C}$, чтобы иметь в нем давление выше атмосферного для предотвращения подсоса воздуха в контур. Для значений температур греющих теплоносителей в диапазоне $100-130{ }^{\circ} \mathrm{C}$ целесообразно применять в утилизационном контуре хорошо известный в холодильной технике и быту газ бутан (R-6O0 по международной классификации) [1].

Бутаны $\left(\mathrm{C}_{4} \mathrm{H}_{10}\right)$ - газообразные, насыщенные углеводороды, без цвета и запаха. Критические параметры бутана имеют значения 38 бар, $152{ }^{\circ} \mathrm{C}$, а давление насыщенных паров при температурах $30 \ldots . .40^{\circ} \mathrm{C}$ составляет $2,8 \ldots .3,75$ бар. Низкие температуры конденсации увеличивают удельную работу, совершаемую бутаном в турбине. Единственным недостатком бутана (как и пентана) является его взрывоопасность при соединении с кислородом, однако этот недостаток научились преодолевать за счет специальных средств, широко применяющихся в конструкции и при эксплуатации газовых компрессоров и турбодетандеров, появившихся в последнее время в массовом количестве [1].

\section{Принцип работы}

Рабочим телом в органическом цикле Ренкина (ОЦ)Р является вещество, имеющее более низкую, чем у воды, температуру кипения. Благодаря этому испарение рабочего тела происходит при относительно низкой температуре, что и позволяет утилизировать низкопотенциальную энергию. На рис. 1 приведена схема, иллюстрирующая принцип работы ОЦР. Принцип работы установки вполне очевиден. На рис. 1 насос закачивает рабочее тело в жидком состоянии в нагреватель, где при высоком давлении оно испаряется за счет источника низкопотенциального тепла, далее пар попадает в турбину, в которой, расширяясь, совершает работу. Вал

$$
-869-
$$




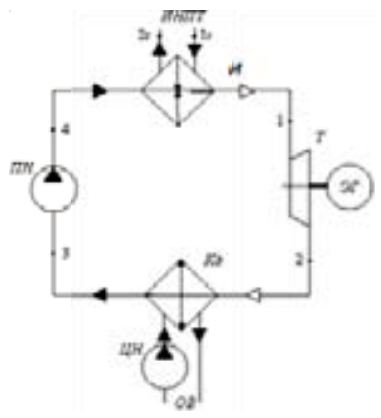

Рис. 1. Принципиальная схема установки, реализующей цикл Ренкина: ИНПТ - источник низкопотенциальной теплоты; Кд - конденсатор; КУ - котел-утилизатор; ОВ - охлаждающая вода; ПН - питательный насос; Т - турбина; ЦН - циркуляционный насос охлаждающей воды; ЭГ электрогенератор

Fig. 1. Schematic diagram of the installation implementing the Rankin cycle: ИНПТ - a source of low - potential heat; Кд - condenser; КУ - boiler - utilizer; OВ - cooling water; ПН - feed pump; Т - turbine; ЦН - cooling water circulation pump; ЭГ - electric generator

турбины вращается и приводит в действие электрогенератор. Отработанный пар охлаждается, и рабочее тело конденсируется. Далее вещество в жидком состоянии попадает в насос и цикл замыкается.

\section{Область применения}

Достоинствами цикла Ренкина по сравнению с циклами Брайтона, Стирлинга и Калины являются относительная простота реализации, дешевизна оборудования и эффективность. Главное достоинство ОЦР - возможность его адаптации к различным источникам тепловой энергии. За счет варьирования рабочего тела его можно использовать в широком диапазоне температур и давлений. В частности, ОЦР можно использовать в бинарном цикле как в высокотемпературной, так и в низкотемпературной области. Рассмотрим наиболее перспективные области применения ОЦР.

\section{Геотермальная энергетика}

В качестве источника тепла для ОЦР на геотермальной электростанции выступают теплые геотермальные воды, которые скважинными насосами из недр земли подаются в испаритель, где и отдают тепло НКТ.

Первая в мире геотермальная электростанция (ГеоТЭС) на НРТ, или, как ее еще называют, бинарная ГеоТЭС, была создана в СССР на Камчатке (Паратунская ГеоТЭС) в 1967 г. Источником теплоты были геотермальные воды с температурой $81{ }^{\circ} \mathrm{C}$, рабочим агентом хладоном R12, вырабатываемой мощностью 680 кВт.

В то же время во всем мире активизируется практическое внедрение бинарных ГеоТЭС (США, Мексика, Аргентина, Исландия, Италия, Австрия, Германия, Португалия, Израиль, Таиланд, КНР, Тайвань, Новая Зеландия, Филиппины, Япония), при этом определяющей является тенденция на создание небольших, полностью автоматизированных, не нуждающихся в постоянном обслуживании модульных установок (рис. 2, 3). Лидером в их производстве (до 1000

$$
-870-
$$




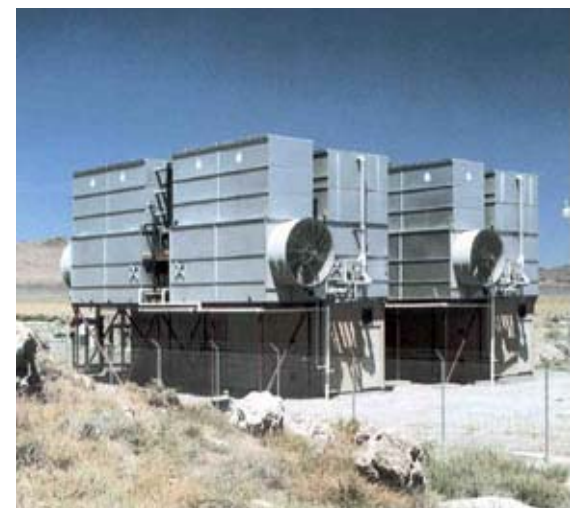

Рис. 2. Бинарная ГеоТЭС WinEagle Developers (Северная Калифорния) фирмы Barber Nichols Engineering Company of Arvada, Colorado

Fig. 2. Binary Geothermal thermal power station WinEagle Developers (Northern California) by Barber Nichols Engineering Company of Arvada, Colorado

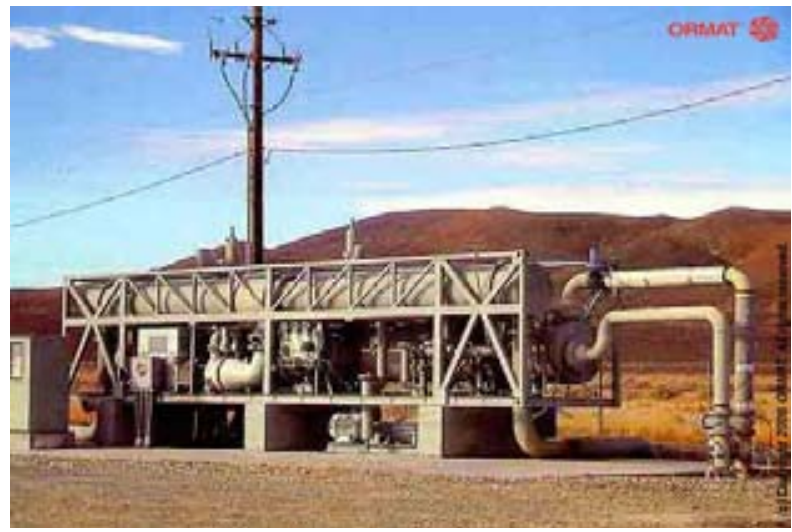

Рис. 3. Бинарная ГеоТЭС TAD’s Enterprises (Невада, США) производства фирмы ORMAT International, Inc

Fig. 3. Binary Geothermal thermal power station Enterprises (Nevada, USA) by ORMAT International, Inc

установленных энергомодулей на пентане мощностью от 40 кВт до 3,5 МВт) является фирма ORMAT (Израиль) и ее дочерние предприятия.

\section{ОЦР на биомассе}

В последнее время, в первую очередь в Европе, большое внимание уделяют внедрению ТЭС с НРТ, поступление теплоты в которые обеспечивается за счет сжигания биомассы (отходов древесины, сельского хозяйства, например соломы, и др.), а также мусора.

Так, в г. Фуссах (Австрия) действует ТЭС на биомассе, где топливом является щепа из отработанной древесины, отходов деревообработки и лесозаготовок. Теплота используется в циклах Ренкина и абсорбционной холодильной машины. Установленная мощность ТЭС 8,7 МВт (1,3 МВт электрическая и 7,4 МВт тепловая). При годовом расходе древесного топлива 78 тыс. м $^{3}$ объем производства составляет: тепловой энергии 43500 МВт, электри- 
ческой - 8250 МВт, холода - 18000 МВт. Вырабатываемая энергия в основном используется на расположенной поблизости фабрике пластмассовых изделий. Суммарные затраты на строительство ТЭС составили 6,14 млн $€$, охладительной станции - 1,35 млн $€$, сети централизованного теплоснабжения к охладительной станции - 0,5 млн $€$. Срок окупаемости -8 лет [2].

На данный момент в Австрии, Германии, Швейцарии и Италии действуют около десятка подобных ТЭС.

\section{ОРЦ и солнечная энергетика}

Одним из перспективных вариантов практического использования энергии Солнца для производства электроэнергии являются солнечные ТЭС на НРТ, обладающие определенными преимуществами по сравнению с фотовольтаическими установками (использующими энергию Солнца): комплектуются более простыми солнечными концентраторами и системой трансформации электрического тока к требуемым параметрам; включение в схему аккумулятора теплоты обеспечивает круглосуточное функционирование станции (ночью за счет теплоты, запасенной днем).

\section{ОЦР для утилизащии производственного тепла}

Большинство металлургических предприятий для производства своей продукции используют печи сжигания, уходящие газы после которых имеют высокую температуру, и часто данное тепло выбрасывается в атмосферу. Одним из таких примеров является процесс металлизации железорудных окатышей во вращающейся печи. Было рассчитано, что для печи с расходом дымовых газов 70-120 нм3/ч при температуре уходящих газов $600-700{ }^{\circ} \mathrm{C}$ мощность турбины составит 800-1500 кВт.

\section{Комбинирование ОЦР}

ОЦР можно использовать с противодавленческими турбинами малой мощности, ГТУ, мини-ТЭЦ.

\section{Использование ОЦР с противодавленческими турбинами малой мощности}

Использование противодавленческих турбин малой мощности с присоеденением выхлопа к сетевым теплообменникам позволяет комбинировать выработку тепло- и электроэнергии. Основной недостаток данного способа - весной при уменьшении тепловой нагрузки вместе с ней уменьшается и количество вырабатываемой электрической, а летом при отсутствии потребителя тепла данная турбина остановливается.

Присоединение к выхлопу такой турбины дает возможность круглогодично работать противодавленческой турбине и дополнительно вырабатывать мощность за счет подключения бутановой турбины. Данная схема представлена на рис. 4.

\section{Использование ОЦР с водогрейным котлом}

Внедрение на водогрейной котельной бутанового контура позволяет создать когенерацию одновременную выработку тепловой и электрической энергии. В зависимости от потребителя

$$
-872-
$$


мини-ТЭЦ может переключаться между режимами выработки как в сторону электроэнергии, так и в сторону тепла за счет изменения расхода воды на испаритель бутана и подачу теплосети. Данная схема изображена на рис. 5.

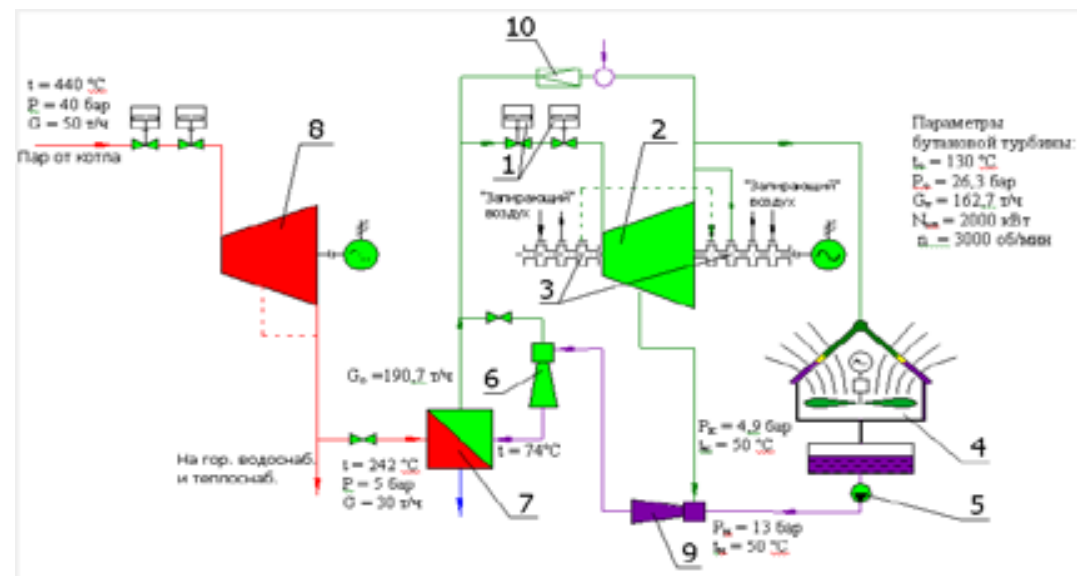

Рис. 4. Тепловая схема энергетической установки с противодавленческой турбиной и бутановым контуром: 1 - стопорный и регулирующий клапаны с пневмоприводом; 2 - бутановая турбина; 3 «сухие» бутановые уплотнения; 4 - воздушный конденсатор; 5 - конденсатный насос; 6 - инжектор; 7 - испаритель бутана; 8 - паровая турбина типа P-6-3,4/0,5; 9 - подогреватель бутана смешивающий струйного типа; 10 - БРОУ

Fig. 4. Thermal scheme of the power plant with backpressure turbine and butane circuit: 1 - stop and control valves with pneumatic drive; 2 - butane turbine; 3 - "dry" butane seals; 4 - air condenser; 5 - condensate pump; 6 - injector; 7 - butane evaporator; 8 - steam turbine of type P-6-3,4/0,5; 9 - butane mixing heater jet type; 10 High - speed reduction unit

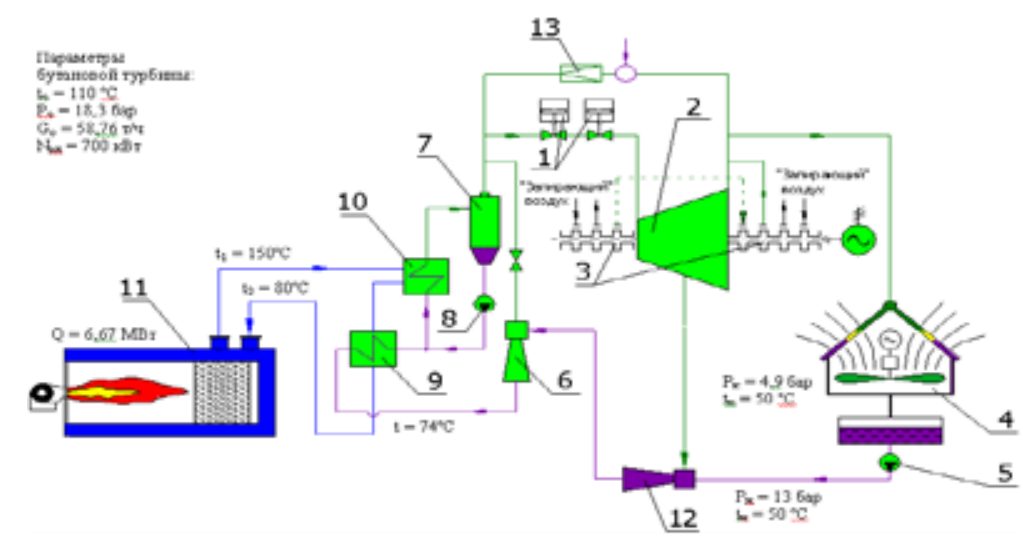

Рис. 5. Схема мини-ТЭЦ с водогрейным котлом и бутановым контуром: 1 - стопорный и регулирующий клапаны с пневмоприводом; 2 - бутановая турбина; 3 - «сухие» бутановые уплотнения; 4 - воздушный конденсатор; 5 - конденсатный насос; 6 - инжектор; 7 - сепаратор; 8 - сепараторный насос; 9 подогреватель бутана; 10 - испаритель бутана; 11 - водогрейный котел КВа 7,56 ГЛЖ; 12 - подогреватель бутана смешивающий струйного типа; 13 - БРОУ

Fig. 5. Scheme of mini - CHP with hot water boiler and butane circuit: 1 - stop and control valves with pneumatic drive; 2 - butane turbine; 3 - "dry" butane seals; 4 - air condenser; 5 - condensate pump; 6 - injector; 7 - separator; 8 - separator pump; 9 - butane heater; 10 - butane evaporator; 11 - hot water boiler КВа 7,56 ГЛЖ; 12 butane heater mixing jet type; 13 - High - speed reduction unit 


\section{Использование ОЦР с ГТУ}

В зависимости от температуры и объема уходящих газов существует два способа надстройки.

1. Надстройка ОЦР к комбинированному ПГУ с подключением ОЦР к теплофикационному отбору паровой турбины.

2. Надстройка ОЦР к ГТУ через водогрейный котел-утилизатор.

Данные способы позволяют вырабатывать дополнительную энергию на уходящих газах ГТУ и утилизировать тепло уходящих газов ГТУ вне зависимости от потребителя тепла (рис. 6, 7).

\section{Выводы}

Применение органического цикла Ренкина позволяет использовать низкопотенциальную тепловую энергию выхлопных газов, геотермальных источников, других тепловых потоков с относительно невысокой температурой. Утилизация данного тепла будет способствовать увеличению тепловой эффективности энергетических предприятий. Выбор рабочего тела для ОЦР существенно влияет на его характеристики и определяется диапазоном эксплуатационных температур и давлений цикла. Достоинствами ОЦР являются:

- отсутствие необходимости перегрева рабочего тела,

- относительно низкая температура рабочего тела на входе в турбину,

- высокая плотность рабочего тела, что позволяет сделать установку более компактной,

- высокое давление пара при конденсации,

- более простая конструкция турбины,

- возможность утилизации тепловой энергии при низкой температуре.

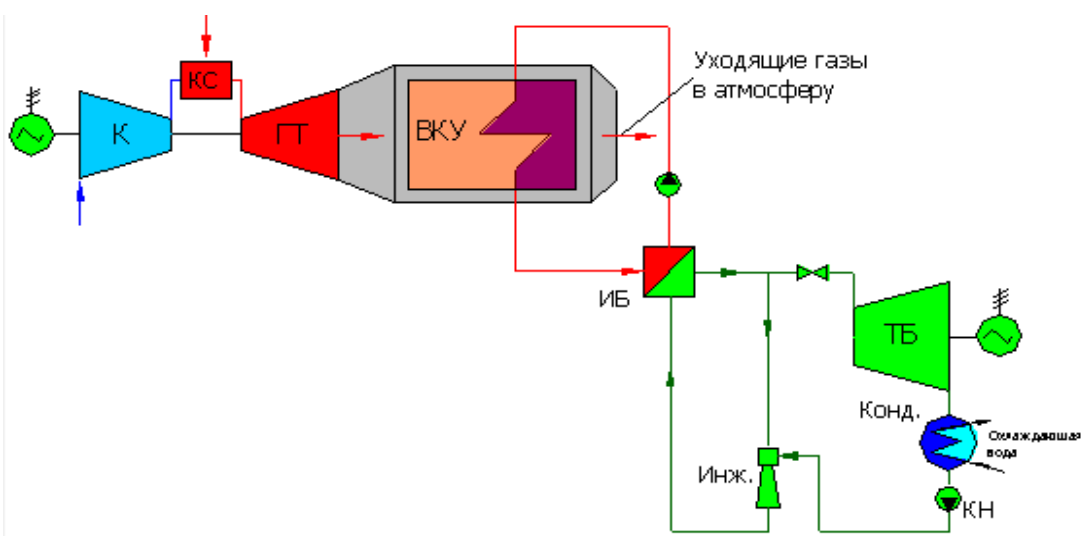

Рис. 6. Схема комбинированной энергетической установки с газовой турбиной, водогрейным КУ и бутановым (пентановым) контуром: К - компрессор; КС - камера сгорания; ГТ - газовая турбина; ВКУ водогрейный котел-утилизатор; ТБ - турбина бутановая; ИБ - испаритель бутана; Инж. - инжектор; КН - конденсатный насос; Конд. - конденсатор

Fig. 6. Scheme of the combined power plant with a gas turbine, hot water boiler - utilization and butane (pentane) circuit: K - compressor; КС - combustion chamber; ГТ - gas turbine; ВКУ - hot water boiler - utilizer; ТБ turbine butane; ИБ - butane evaporator; Инж. - injector; КН - condensate pump; Конд. - condenser 


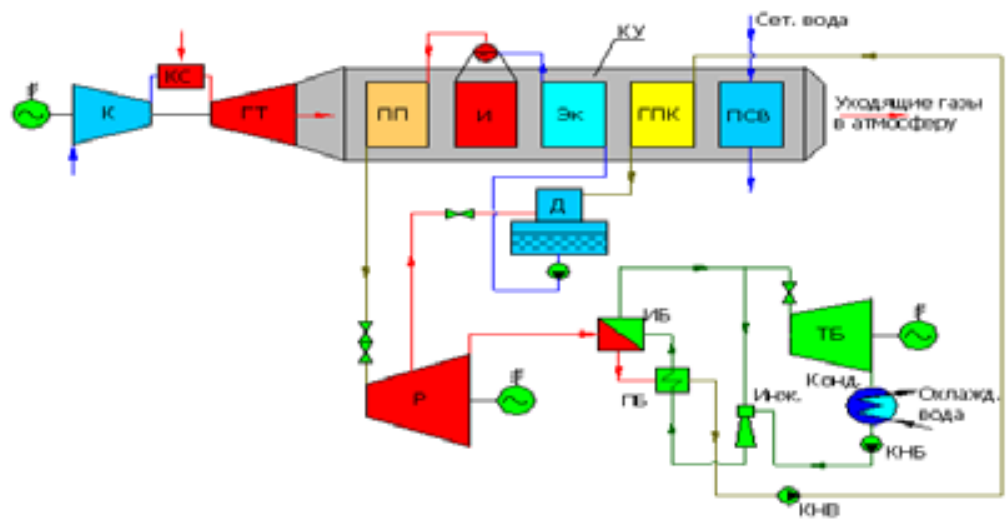

Рис. 7. Схема комбинированной энергетической установки, включающей ПГУ с паровым котломутилизатором и бутановый (пентановый) контур: К - компрессор; КС - камера сгорания; ГТ - газовая турбина; КУ - котел - утилизатор для водяного пара; ПП - пароперегреватель; И - испаритель; Эк экономайзер; ГПК - газовый подогреватель конденсата; ПСВ - подогреватель сетевой воды; Д-деаэратор; P - паровая турбина с противодавлением; ИБ - испаритель бутана; ПБ - подогреватель бутановый; Инж. - инжектор; Конд. - конденсатор; КНВ - конденсатный насос водяной; КНБ - конденсатный насос бутановый

Fig. 7. The Scheme of the combined power plant, including CCGT with a steam boiler-utilizer and butane (pentane) circuit: $\mathrm{K}$ - compressor; $\mathrm{KC}$ - combustion chamber; $Г \mathrm{~T}$ - gas turbine; $\mathrm{KУ} \mathrm{-} \mathrm{boiler} \mathrm{-} \mathrm{utilizer} \mathrm{for} \mathrm{water} \mathrm{vapor;}$ ПП - superheater; И - evaporator; ЭК - economizer; ГПК - gas condensate heater; ПСВ - water heater; Д deaerator; Р - steam turbine with backpressure; ИБ - butane evaporator; ПБ - butane heater; Инж. - injector; Конд. - condenser; КНВ - condensate water pump; КНБ - condensate pump butane

\section{Список литературы}

[1] Гринман М.И., Фомин В.А. Перспективы применения энергетических установок малой мощности с низкокипящими рабочими телами. Энергомашиностроение, 2006, 1, 63-69. [Grinman M.I., Fomin V.A. Prospects for the use of small-scale power plants capacities with lowboiling working bodies. Power plant engineering, 2006, 1, 63-69. (In Russian)]

[2] Tchanche B.F., Lambrinos Gr., Frangoudakis A., Papadakis G. Low-grade heat conversion into power using organic Rankine cycles - A review of various applications. Renewable and Sustainable Energy Reviews, 2011, 15(8), 3963-3979.

[3] Chen H., Goswami D.Y., Stefanakos E.K. A review of thermodynamic cycles and working fluids for the conversion of low-grade heat. Renewable and Sustainable Energy Reviews, 2010, 14, 3059-3067.

[4] Li J., Pei G., Li Y., Wang D., Ji J. Energetic and exergetic investigation of an organic Rankine cycle at different heat source temperatures. Energy, 2012, 38(1), 85-95.

[5] Kang S.H. Design and experimental study of ORC (organic Rankine cycle) and radial turbine using R245fa working fluid Energy, 2012, 41, 514-524.

[6] Fernandez-Garcia A., Zarza E., Valenzuela L., Pérez M. Parabolic-trough solar collectors and their applications. Renewable and Sustainable Energy Reviews, 2010, 14, 16951721.

[7] Delgado-Torres A.M., Garcia-Rodriguez L. Analysis and optimization of the lowtemperature solar organic Rankine cycle (ORC). Energy Conversion and Management, 2010, 51, 2846-2856. 
[8] Rentizelas A., Karellas S., Kakaras E., Tatsiopoulos I. Comparative techno-economic analysis of ORC and gasification for bioenergy applications. Energy Conversion and Management, 2009. 50(3), 674-681.

[9] DiPippo R. Second Law assessment of binary plants generating power from low-temperature geothermal fluids. Geothermics, 2004, 33, 565-586.

[10] Kanoglu M., Bolatturk A. Performance and parametric investigation of a binary geothermal power plant by exergy. Renewable Energy, 2008, 33, 2366-2374.

[11] Yari M. Exergetic analysis of various types of geothermal power plants. Renewable Energy, 2010, 35, 112-121.

[12] Shengjun Z., Huaixin W., Tao G. Performance comparison and parametric optimization of subcritical Organic Rankine Cycle (ORC) and transcritical power cycle system for low-temperature geothermal power generation. Applied Energy, 2011, 88, 2740-2754.

[13] Madlool N.A., Saidur R., Hossain M.S., Rahim N.A. A critical review on energy use and savings in the cement industries. Renewable and Sustainable Energy Reviews, 2011, 15, 2042-2060.

[14] Yu G., Shu G., Tian H., Wei H., Liu L. Simulation and thermodynamic analysis of a bottoming Organic Rankine Cycle (ORC) of diesel engine (DE). Energy, 2013, 51, 281-290.

[15] Bombarda P., Invernizzi C.M., Pietra C. Heat recovery from Diesel engines: A thermodynamic comparison between Kalina and ORC cycles. Applied Thermal Engineering, 2010, 30, 212-219.

[16] Srinivasan K.K, Mago P.J., Krishnan S.R. Analysis of exhaust waste heat recovery from a dual fuel low temperature combustion engine using an Organic Rankine Cycle. Energy, 2010, 35, 2387-2399.

[17] Sprouse C., Depcik C. Review of organic Rankine cycles for internal combustion engine exhaust waste heat recovery. Applied Thermal Engineering, 2013, 51, 711-722.

[18] Invernizzi C., Iora P., Silva P. Bottoming micro-Rankine cycles for micro-gas turbines. Applied Thermal Engineering, 2007, 27, 100-110.

[19] Chacartegui R. et al. Alternative ORC bottoming cycles for combined cycle power plants. Applied Energy, 2009, 86, 2162-2170.

[20] Saleh B., Koglbauer G., Wendland M., Fischer J. Working fluids for low-temperature organic Rankine cycles. Energy, 2007, 32, 1210-1221. 